\title{
Audit Firm Rotation, Audit Firm Tenure and Earnings Conservatism
}

\author{
Stefan Thomas Kramer \\ Amsterdam Business School, University of Amsterdam, Netherlands \\ E-mail: s.kramer@nl.pwc.com \\ Georgios Georgakopoulos (Corresponding author) \\ Amsterdam Business School, University of Amsterdam, Netherlands \\ E-mail: g.georgakopoulos@uva.nl \\ Ioannis Sotiropoulos \\ Department of Finance and Auditing, Technological Educational Institute of Epirus, Greece \\ E-mail: sotiropoulosioan@yahoo.gr \\ Konstantinos Z. Vasileiou \\ Department of Business Planning \& Information Systems, TEI of Patras, Greece \\ E-mail: vasileiou@teipat.gr
}

Received: March 1, 2011 Accepted: March 25, $2011 \quad$ doi:10.5539/ijbm.v6n8p44

\begin{abstract}
This study aims to contribute to the debate around the possibility of mandating audit firm rotation. Specifically, it examines conservatism as an attribute of earnings quality, which has not attracted particular attention in the auditor rotation research. Applying regression analyses on a sample, which consists of U.S. firms for the period 1980-2006, our findings indicate that conservatism in reported earnings increases after the rotation of the audit firm. However, our results lack significance. Moreover, our results indicate that conservatism in reported earnings decreases as the tenure of the audit firm lengthens. Consequently, mandating audit firm rotation might have a positive impact on conservatism and thus on the quality of reported earnings. However, additional analysis shows that this impact might not have existed in the later part of the sample period.
\end{abstract}

Keywords: Audit firm rotation, Conservatism, Earnings quality, U.S. firms

\section{Introduction}

Auditor rotation has been debated in the United States for more than 45 years (Myers et al., 2003). However, the concerns about audit failure have significantly increased in the last years, especially after the accounting scandals occurred during the period 2001-2003. These concerns have resulted in numerous new rules and further regulation of financial accounting and the auditing profession. The most important action was the implementation of mandatory audit partner rotation by the Sarbanes-Oxley Act on July 25, 2002 (hereafter referred to as SOX or the SOX Act) in the United States. Specifically, section 203 of the SOX Act states that "it shall be unlawful for a registered public accounting firm to provide audit services to an issuer if the lead audit partner (having primary responsibility for the audit) or the audit partner responsible for reviewing the audit that is assigned to perform those audit services has performed audit services for that issuer in each of the 5 previous fiscal years of that issuer". The primary motivation of the SOX Act regarding the audit partner rotation provision was to have a set of 'fresh eyes' examining the client's financial statements (Hatfield et al., 2007).

In the above context of mandatory audit partner rotation we attempt to address here the relation between audit-firm rotation, audit firm tenure and conservatism as an attribute of earnings quality. In this light our paper proceeds as follow: In the next section we briefly discuss the literature review in relation to audit rotation, how auditor independence affects earnings' quality, and earnings conservatism. We then present our research hypotheses, methodology and data sample. This is followed by our research results. Our paper concludes with a discussion of our findings, limitations of our work and areas for future research.

\section{Literature Review}

\subsection{The auditor rotation debate}

Auditor rotation can either take the form of audit firm rotation, where the complete audit firm is rotated off the 
client after a pre-determined period has expired, or audit partner rotation, where only the responsible partner is internally rotated off the client. Since mandatory auditor rotation was posed as a possible solution to the auditor independence problem, most countries have adopted mandatory partner rotation in some way or another. The subject has extensively been addressed in different contexts by researchers around the globe (e.g. Chen et al., 2008; Jenkins and Velury, 2008; Kaplan and Mauldin, 2008) (Note 1). Interestingly, most of the research seems to have provided results in disfavour of mandatory auditor rotation. Nevertheless, there is still an ongoing discussion whether the rules with regard to audit partner rotation should be extended to include mandatory rotation of audit firms.

The associated costs and benefits of mandatory audit firm rotation have been widely discussed (Cameran et al., 2005). When SOX mandated audit partner rotation in 2002, it also asked the U.S. General Accounting Office (GAO) to study the expected effects of mandatory audit firm rotation. The report following that study indicated that mandatory audit firm rotation could strengthen independence in appearance, but that significant costs would be associated with it $(\mathrm{GAO}, 2003)$. Further, the report indicated that the audit partner rotation would achieve much of the benefits of audit firm rotation with regard to independence, which is consistent with results of Kaplan and Mauldin (2008). The latter found that audit firm rotation would not strengthen independence in appearance compared to audit partner rotation. On the other hand, audit partner rotation does not overcome the economic incentive of the audit firm to retain the relationship with the client (Imhoff, 2003).

Adversary to mandatory auditor rotation, Johnson et al. (2002) found that short audit firm tenure (2-3 years) compared to medium audit firm tenure (4-8 years), is associated with lower financial reporting quality. As proxies for financial reporting quality they used the absolute value of unexpected accruals and the persistence of the accrual components of earnings. Carcello and Nagy (2004) researched the audit firm tenure in relation to the fraudulent financial reporting and confirmed the results of Johnson et al. (2002). They found that, given short audit firm tenure, fraudulent financial reporting is significantly more likely. Further, they documented no association between long audit firm tenure and fraudulent financial reporting. Geiger and Raghunandan (2002) tested for an association between the type of audit opinion issued on the financial statements prior to bankruptcy and audit firm tenure. Their results indicated that audit reporting failures occurred significantly more when the audit firm tenure was short. With respect to how auditor independence in relation to auditor tenure is perceived, Ghosh and Moon (2004) found that investors perceive longer auditor tenure as improving audit quality. Jackson et al. (2008) confirmed this perception of investors by providing evidence that audit quality increases with audit firm tenure. They concluded that mandating audit firm rotation provides minimal benefits compared to audit partner rotation.

In favour of mandatory auditor rotation, the experimental study of Dopuch et al. (2001) provided evidence that auditors are less willing to issue biased reports under a mandatory rotation environment. Wang and Tuttle (2009) suggested that audit firms would be willing to concede some items in the short-term in order to preserve the long-term relationship with their clients. This is consistent with audit firms having an incentive to bond with their clients to ensure profits from future audits (Imhoff, 2003; Kaplan and Mauldin, 2008). Mandatory auditor rotation could overcome such bias, because a long-term relationship with the client cannot be developed. Wang and Tuttle (2009) further found that auditors become less cooperative with clients if mandatory audit firm rotation is imposed. Imhoff (2003) stated that mandatory audit firm rotation would reduce any tendencies of auditors to not report specific issues, because another audit firm will soon take over the audit and might discover any negligence of the previous audit firm. Contrary to the study of Ghosh and Moon (2004), in a more recent study, Dao et al. (2008) documented evidence that shareholders view longer auditor tenure as negatively affecting audit quality.

Opponents of auditor rotation indicate that audit costs would increase dramatically due to the lack of knowledge of the auditor in the initial years of the engagement. Proponents claim that those costs outweigh the costs of losses due to corporate collapses that are the result of decreases in audit quality (Jackson et al., 2008). An interesting view on the cost argument is that of Imhoff (2003). He argued that increased costs, as a result of the audit in the initial years of the auditor-client relationship, are passed on to the shareholders. Imhoff (2003) expected that shareholders are very willing to incur those costs if it guarantees them of an independent audit. The only question in this respect is how many costs shareholders are willing to incur.

Only a small amount of papers have considered audit partner or audit firm rotation directly. The evidence of other papers rather allows determining implications of auditor rotation. The main focus of researchers on the subject matter has been on the association between the length of the auditor-client relationship, hereafter called auditor tenure, and earnings quality. Those researchers have generally suggested that shorter (longer) auditor tenure is associated with lower (higher) earnings quality (e.g. Johnson et al., 2002; Myers et al., 2003). Strikingly, while it is audit partner rotation that has become a mandatory requirement in a lot of countries, only a very limited amount of research has focused on the effects of audit partner rotation.

It is not surprising that audit partner rotation has not been researched extensively. Data regarding audit partner rotation is not publicly available and audit firms are generally not willing to provide these data, which limits research to the investigation of the possible effects of mandatory audit firm rotation (Note 2). It can, however, be 
stated that audit firm rotation automatically implies audit partner rotation. That is, unless the lead audit partner and the client move together to another audit firm, but our study does not assume a high possibility of such a situation. Turnovers of auditors within the audit firm may (and will) occur, but this unlikely affects the economic incentives of the audit firm with respect to the client. Moreover, audit documents and approaches survive an internal turnover of audit staff (Johnson et al., 2002). Interestingly, while the U.S. and many other countries have established laws that require rotation of the lead audit partner after a specified amount of years, Hamilton et al. (2005) argue that the requirement is not well founded because of an absence of evidence on the extent to which partner rotation impacts audit quality and earnings quality (Note 3 ).

Overall, the debate mainly seems to focus on whether auditor independence is impaired when the auditor-client relationship is longer and how this impaired independence affects the quality of financial reporting.

\subsection{Earnings quality and auditor independence}

To address the relation between audit firm rotation, audit firm tenure and conservatism as an attribute of earnings quality, an understanding of earnings quality is required. According to most studies, both the company's management and the audit firm determine the quality of financial reporting, since financial statements are perceived as a joint product (Antle and Nalebuff, 1991; Hamilton et al., 2005). Assuming that auditor independence directly affects the quality of the audit, any change in auditor independence would be translated in a change in the quality of the financial statements, hence the quality of reported earnings.

A common argument of proponents of auditor rotation is that auditors would provide more support for aggressive accounting by the client's management when their independence is impaired, which eventually would result in failures to detect material errors (Myers et al., 2003). Further, management is likely to gain more reporting flexibility when the auditor-client relationship lengthens, which could result in earnings management quality (Davis et al., 2000).

Hamilton et al. (2005) stated that most of the criticism with regard to reduced auditor independence and its effect on earnings quality "seems to be premised on instances of overly aggressive reporting, whereby the underlying deterioration in the profitability of collapsing firms has been concealed". Aggressive reporting can be defined as using reporting methods that portray "the client's financial situation favourably when that method is not clearly indicated by the facts and relevant professional literature" (Hackenbrack and Nelson, 1996). These methods are likely to result in an increase of earnings and/or liquidity because managers have incentives to bias estimates of future values in favour of current earnings (Basu, 1997).

If auditors are more independent, it will be more likely that they stand up against attempts of manipulating earnings management, which would be reflected in more income decreasing items being recorded (Kaplan and Mauldin, 2008). If audit firm rotation can influence the independence of the auditor and in turn aggressive reporting, a variation in earnings reflecting losses on a more timely basis than gains would exist after audit firm rotation. Francis et al. (2005) argued that conservative accounting results in higher accounting quality. This research posits that the level of earnings conservatism in reported earnings can be used to identify changes in the quality of those earnings after audit firm rotation.

\subsection{Earnings conservatism}

Although conservatism plays an important role in accounting practice and theory, there exists no authoritative definition of it (Givoly et al., 2007). The only 'official' definition of conservatism might be the one stated in the Statement of Concepts No. 2 of the FASB (1980), wherein it is defined as "a prudent reaction to uncertainty to try to ensure that uncertainty and risks inherent in business situations are adequately considered". However, this definition is not often referred to in prior research. Rather, the definition of Basu (1997), or an adaptation of it, is used. Basu (1997) has argued that unrealized losses are typically recognized earlier than unrealized gains. His main finding was that reported earnings respond more quickly to bad news than good news, when bad and goods news are respectively proxied by negative and positive unexpected annual stock returns. Basu (1997) defined conservatism as "earnings being more timely and more sensitive concurrently to publicly available bad news than good news".

Following the research of Basu (1997), prior research has identified two different forms of conservatism in financial reporting: unconditional and conditional conservatism (Note 4). Unconditional conservatism describes a bias towards reporting low book values of equity through reporting lower income, such as the immediate expensing of costs of most intangibles (Ball and Shivakumar, 2005; Ryan, 2006). Conditional conservatism, or what Basu (1997) calls asymmetric timeliness of loss recognition, describes an equivalent bias, however, conditional on the fact that the firm experiences contemporaneous economic losses, which happens with impairment accounting for assets (Ball and Shivakumar, 2005; Ryan, 2006). Unconditional conservatism also follows from GAAP because the principles allow using conservative accounting methods and sometimes even prescribe conservative accounting methods (Amir et al., 2009).

Following Jenkins and Velury (2008) and Hamilton et al. (2005), our work focuses on conditional conservatism because this definition captures the timeliness of loss recognition. In the remaining part of this paper, where the word 'conservatism' is used, refers to the conditional form of conservatism. 
Higher levels of conservatism have been interpreted as suggestive of earnings that are of higher quality and explanations for conservative reporting all suggest that conservatism is a benefit for the users of financial statements (Watts, 2003a; Myers et al., 2003). This is generally reflected in indications of researchers that conservatism plays an important role in contracting. Conservatism is said to be consistent with the contracting demand for financial reporting (Ball and Shivakumar, 2005; Hamilton et al., 2005). It reduces managers' attempts to bond against exploiting their asymmetrically informed position relative to other stakeholders (Basu, 1997). Asymmetric verifiability imposes a limitation to that bias. By enhancing contracting efficiency, conservatism contributes to financial reporting quality (Watts, 2003a). The contracting efficiency also follows from the fact that earnings flow into balance sheet accounts which then make leverage and dividend restrictions binding more quickly (Ball et al., 2000).

\subsection{Aim and Research Hypotheses of the study}

Earnings conservatism in relation to auditor rotation and auditor tenure has only been investigated by Hamilton et al. (2005) and Jenkins and Velury (2008) yet. Since their evidence seems to be mixed and somewhat contradictory, these two papers form the basis for the hypotheses of our study.

Hamilton et al. (2005) tried to "identify whether audit partner rotation is associated with an incremental increase in earnings conservatism". They documented evidence of more conservative reporting after the rotation of an audit partner, which was reflected in an increase in the asymmetrically timely loss recognition when the audit partner was changed. However, there is no specific evidence available that confirms a similar association between audit firm rotation and earnings conservatism. However, a rotation of the audit firm automatically implicates that a new audit partner will be responsible for the client. It is therefore expected that similar results will be found for earnings conservatism in association with audit firm rotation. One could further argue that, because auditors face a higher litigation risk in the initial years of the engagement (Stice, 1991; Myers et al., 2003), they are likely to be more careful, hence require more conservative reporting. This leads to our first hypotheses:

Hypothesis 1: Audit firm rotation is associated with an increase in the level of conservatism in reported earnings in the year after rotation.

In order to investigate the persistence of any effect of audit firm rotation on the level of conservatism in reported earnings, this study also investigates the association between audit firm tenure and earnings conservatism. Opponents of mandatory auditor rotation acknowledge the view of proponents that auditor independence decreases as tenure lengthens (Cameran et al., 2005). Amir et al. (2009) also found a positive association between measures of auditor independence and timely recognition of losses. It can thus be expected that the level of conservatism in reported earnings is lower for long audit firm tenure than it is for medium and short audit firm tenure. This reasoning leads to our second hypothesis:

Hypothesis 2: The level of conservatism in reported earnings is higher for short audit firm tenure than it is for medium and long audit firm tenure.

Jenkins and Velury (2008) examined the association between earnings conservatism and auditor tenure by using a variation of the model by Basu (1997). They found a significant positive association between earnings conservatism and audit firm tenure. When they partitioned their observations into short (2-3 years), medium (4-8 years) and long tenure (9+ years), their results indicated an increase in earnings conservatism between short and medium tenure, which does not deteriorate over long tenure. Contrary to these results, Hamilton et al. (2005) found some evidence of continued conservatism after audit partner rotation, but they indicated that the level of conservatism slowly reduces as the tenure lengthens. The evidence regarding auditor tenure and earnings conservatism thus not seems to be conclusive, indicating the need for more research in this field.

\section{Methodology and Data Collection}

\subsection{Methodology}

\subsubsection{Measuring conservatism}

While prior research has often used absolute and signed abnormal accruals as proxies for earnings or audit quality (Chi et al., 2009), this study uses the level of conservatism in reported earnings as a proxy for earnings quality. As discussed earlier the most common measure of conservatism is introduced by Basu (1997), which has gained wide acceptance in the accounting literature (Jenkins and Velury, 2008). Under his definition of conservatism, Basu (1997) used negative unexpected returns as a proxy for bad news and positive unexpected returns as a proxy for good news. Although the measure by Basu (1997) has received some criticism, it still receives a lot of support as a measure of conservatism in recent research (Jenkins and Velury, 2008) (Note 5). Further, after conducting an extensive review of literature and measures regarding conservatism, Ryan (2006) concludes that researchers should use the asymmetric timeliness of loss recognition as the primary measure of conservatism.

For his measure of conservatism, Basu (1997) used a Beaver et al. (1980) reverse regression to regress annual earnings on current unexpected annual returns (Note 6). In this study, following Jenkins and Velury (2008), the 
model of Basu (1997) to test for conservatism in earnings, without taking into account audit firm rotation, is applied as follows:

$$
E A R N_{i t}=\beta_{0}+\beta_{1} R E T_{i t}+\beta_{2} D R E T_{i t}+\beta_{3} R E T_{i t} * D R E T_{i t}+\varepsilon_{i t}
$$

where for firm $i$ in year $t$ : EARN is the earnings before extraordinary items deflated by total assets; RET is the fiscal year stock return (Note 7); and DRET is the dummy variable set equal to 1 if RET $<0$, otherwise set equal to zero.

In Model (1), $\beta_{1}$ measures the response of earnings to positive returns and $\beta_{1}+\beta_{3}$ measures the response of earnings to negative returns. Reported earnings are conservative when $\beta_{3}$ is significant and positive (Jenkins and Velury, 2008). Coefficient $\beta_{3}$ measures the asymmetric timeliness of loss recognition and has been called the differential timeliness (DT) measure (Basu, 1997).

Model (1) is further extended to include a variable which measures the effect of audit firm rotation on the DT measure. This results in the following model:

$$
\begin{aligned}
E A R N i t= & \beta_{0}+\beta_{1} R E T_{i t}+\beta_{2} D R E T_{i t}+\beta_{3} R E T_{i t} * D R E T_{i t}+\beta_{4} R O T A T_{i t}+\beta_{5} R O T A T_{i t} * R E T_{i t}+\beta_{6} R O T A T * D R E T_{i t} \\
& +\beta_{7} R O T A T_{i t} * R E T_{i t} * D R E T_{i t}+\varepsilon_{i t}
\end{aligned}
$$

where, for firm $i$ in year $t$ : ROTAT is a dummy variable set equal to 1 if audit firm rotation has occurred in the current year, otherwise set equal to zero; and all other variables are as stated earlier.

If audit firm rotation is associated with an increase in conservatism, a positive correlation between returns and earnings attributable to conservatism (i.e. $\mathrm{RET}_{i t} * \mathrm{DRET}_{i t}$ ) will be enhanced at the time of audit firm rotation. This association is measured by coefficient $\beta_{7}$, which is expected to be positive if Hypothesis 1 is true.

The model includes a three-way interaction. In Model (1), coefficient $\beta_{3}$ measures whether earnings are conservative. This coefficient $\beta_{3}$ is a measure of the interaction between the variables RET and DRET. The higher the value of $\beta_{3}$, the more conservative reported earnings are. When investigating earnings conservatism given that audit firm rotation has occurred, a third variable needs to be inserted to make it possible to measure the interaction between RET, DRET and audit firm rotation. Audit firm rotation is measured by the dummy variable ROTAT. The three-way interaction effect is measured by coefficient $\beta_{7}$ in Model (2).

\subsubsection{Measuring audit firm tenure}

In order to investigate the persistence of an effect of audit firm rotation on the level of conservatism in reported earnings, tests for differences in the level of conservatism for different audit firm tenures are applied. The tests follow the tenure categorization of Johnson et al. (2002), which has also been used by Jenkins and Velury (2008). When the audit firm has audited the client for a period of up to three years, tenure is defined as short, for 4-8 years medium and for over 9 years long (Stice, 1991; Johnson et al., 2002).

To investigate differences between the three tenure periods, observations are assigned to one of three subsamples (short, medium and long). Then, Model (1) is used to determine the level of conservatism inherent in the observations included in the samples. A higher coefficient $\beta_{3}$ for the short tenure sample compared to the medium and long tenure subsamples would indicate that conservatism in reported earnings decreases when audit firm tenure lengthens. This would provide evidence in favour of Hypotheses 2 and would indicate that the level of conservatism in reported earnings is not persistent over the entire auditor-client relationship.

\subsubsection{Ball and Shivakumar measure of conservatism}

In order to test whether an alternative measure of conservatism provides other, more significant results, our analysis is replicated using the model presented by Ball and Shivakumar (2005). Ball and Shivakumar (2005) performed a regression of accounting accruals on operating cash flows. Their argument is that the timely recognition of gains and losses is based on expected unrealized cash flows, which is therefore accomplished through accruals. Further, they stated that "economic gains are more likely to be recognized when they are realized, and hence accounted for on a cash basis".

Their model is applied as follows, with additional interaction terms to capture the effect of audit firm rotation on the association between accruals and operating cash flows:

$$
\begin{aligned}
A C C_{i t}= & \beta_{0}+\beta_{1} C F O_{i t}+\beta_{2} D_{C F O_{i t}}+\beta_{3} C F O_{i t} * D C F O_{i t}+\beta_{4} R_{\text {ROTAT }}+\beta_{5} R_{i t} O T A T_{i t} * C F O_{i t}+\beta_{6} R O T A T * D C F O_{i t} \\
& +\beta_{7} R O T A T_{i t} * C F O_{i t} * D C F O_{i t}+\varepsilon_{i t}
\end{aligned}
$$

where ACC is accruals deflated by total assets; CFO is cash flow from operations deflated by total assets; DCFO is a dummy variable set equal to 1 if $\mathrm{CFO}<0$, otherwise set equal to zero; and all other variables are as stated earlier.

If audit firm rotation is associated with an increase in conservatism in reported earnings, a positive correlation between operating cash flow and accruals attributable to conservatism (i.e. $\mathrm{CFO}_{i t} * \mathrm{DCFO}_{i t}$ ) will be enhanced at the time of audit firm rotation (Hamilton et al., 2005). This association is measured by the coefficient $\beta_{7}$, which is expected to be positive.

In order to obtain additional evidence regarding Hypothesis 1, the initial model of Ball and Shivakumar (2005) is 
applied. This model has the same form of Model (1), but earnings and returns are replaced by, respectively, accruals and cash flow from operations. This results in the following model:

$$
A C C_{i t}=\beta_{0}+\beta_{1} C F O_{i t}+\beta_{2} D C F O_{i t}+\beta_{3} C F O_{i t} * D C F O_{i t}
$$

where, all variables are as earlier stated.

\subsection{Data collection}

\subsubsection{Sample of the study}

Our sample consists of firm-year observations for the period 1980 to 2006 from the Compustat North America Industrial Annual database (Note 8). In order to include a firm-year observation in the sample, data with regard to fiscal year-end (Compustat \#FYR), audit firm (Compustat \#149), earnings before extraordinary items (Compustat \#18), year-end stock price (Compustat \#199), shares outstanding (Compustat \#25) and assets (Compustat \#6) had to be available. All variables are measured per share. In order to include only the information that the auditor could have observed and that the market knows ex ante and to exclude any reaction to earnings information, fiscal year returns are used (Jenkins and Velury, 2008).

In order to control heteroskedasticity, earnings are deflated by total assets (Christie, 1987). Removing the lower and top $1 \%$ of the observations for all variables mitigated the effect of outliers (Note 9). Next, only firms with a December fiscal year-end were included in the sample. The occurrence of audit firm rotation was derived from the audit firm data and could only be determined when data of subsequent financial years were available. When rotation could not be determined with certainty, the observation was excluded from the sample. The above screenings resulted in a final sample of 11,643 firm-year observations. Some additional tests have additional data requirements, which reduced the sample size. These requirements are described before the results of those tests are presented.

Several audit firm mergers have occurred during the sample period (Note 10). If a merger took place and the client of the initial firms became a client of the new combined audit firm, this was treated as a continuation of the auditor-client relationship. It was assumed that no rotation took place at that moment.

Table 1 presents descriptive statistics for the full sample and the sample partitioned into rotation and no rotation firm-years. The EARN variable is stated in millions, which results in low values. The firm-year observations contained a total of 460 instances of audit firm rotation, which is equal to $4.1 \%$ of the total firm-year observations included in the sample. Panel A of Table 1 shows a negative mean for the RET variable. This is remarkable, since the mean of the RET variable appears to be generally positive in prior research (Hamilton et al., 2005; Jenkins and Velury, 2008). However, there are no indications that this would bias the results.

Panel B of Table 1 shows that the variables EARN, RET and DRET differ significantly between the rotation and no rotation subsamples. The differences can be interpreted as initial evidence that earnings are affected by audit firm rotation.

The use of the model by Ball and Shivakumar (2005) required data regarding cash flow from operations (Compustat \#185) to be available. This data was already collected during the initial sample selection. As a result, this requirement did not change the number of firm-year observations in the sample $(n=11,643)$. Cash flow from operations is, like earnings in Models (1) and (2), deflated by total assets (Christie, 1987). Accounting accruals is calculated as the difference between earnings before extraordinary items and cash flow from operations (Jenkins and Velury, 2008), which is then also deflated by total assets.

\section{Research Results}

\subsection{Earnings conservatism and audit firm rotation}

The results of the regression of Model (1) are presented in Table 2. Coefficient $\beta_{3}$ is positive and significant for all firm-year observations, which is consistent with prior research. The bad news coefficient $\beta_{3}$ is much larger than the good news coefficient $\beta_{1}$, indicating that earnings reflect bad news on a more timely basis than good news. The value of the adjusted $\mathrm{R}^{2}$ for all firms is low, but this is consistent with prior research (Basu, 1997; Basu et al., 2001; Hamilton et al., 2005; Lobo and Zhou, 2006).

When the sample is partitioned into rotation and no rotation firm-year observations, a higher coefficient $\beta_{3}$ and a higher $\mathrm{R}^{2}$ are observed for the rotation subsample compared to the no rotation subsample. This provides some initial evidence that audit firm rotation is associated with higher levels of conservatism in reported earnings. However, the difference between the coefficients is only $0.0062(0.0288-0.0226)$. A z-test for the significance of the difference between the coefficients was applied and indicated no significant difference $(z=0.91)$ (Note 11).

Alternatively, Hypothesis 1 is tested using Model (2). The results of the regression are presented in Table 3.

Although $\beta_{7}$ is positive, as was expected, it is not significant. Moreover, the $\mathrm{R}^{2}$ of 5.90 is not a considerable improvement compared to the $\mathrm{R}^{2}$ of 5.80 presented in Table 2 . This indicates no particular improvement in the explanatory power of the model by the addition of the ROTAT variable. However, a low $\mathrm{R}^{2}$ for this regression seems to be consistent with the research by Hamilton et al. (2005) and Jenkins and Velury (2008).

Overall, the signs of coefficients are consistent with those found by Hamilton et al. (2005). The values of 
coefficients $\beta_{0}, \beta_{1}, \beta_{2}$, and $\beta_{3}$ stay consistent with those presented in Table 2, which indicates no specific problems due to the inclusion of the ROTAT variable. Looking at the implications of these results, there is not enough evidence to conclude that audit firm rotation is associated with higher levels of conservatism in reported earnings in the year after rotation. However, it should be noted that the signs of the coefficients do indicate that such an association exists. The results are thus somewhat in favour of Hypothesis 1.

The lack of significant results in the above analysis could be due to the use of the Basu (1997) model. Although the DT measure has received a lot of support as a measure of conservatism (Jenkins and Velury, 2008), there are indications that characteristics of the information environment, which are not related to conservatism, affect the DT measure. According to Givoly et al. (2007), the lack of a significant, positive DT measure, as observed here, could be the result of a small number of negative returns observations. However, this is not the case in the sample used here, as the mean RET is negative (see Table 1). They also show that the DT measure is likely to suffer from measurement errors or downward biases that exceed those found in other measures of conservatism. The measure is further said to capture only one dimension of conservative reporting and not the overall reporting conservatism inherent in the entity (Ball and Shivakumar, 2005). The DT measure should therefore be used in conjunction with other measures of conservatism (Givoly et al., 2007).

Besides the possible measurement error included in the DT measure, the use of a single measure of conservatism would not suffice given that no single definition of conservatism exists. An alternative measure of conservatism is therefore applied.

\subsection{Ball and Shivakumar measure of conservatism}

Descriptive statistics with respect to the variables of Model (3) are presented in Table 4. Panel B shows that the mean for the ACC variable is -0.0005 for the rotation subsample and 0.0009 for the no rotation subsample. The t-test indicated that the difference is significant. Other variables in the model do not differ significantly.

The results of the regression of Model (3) are presented in Table 5. The coefficient $\beta_{7}$ is positive and significant, which provides evidence that audit firm rotation is associated with an increase in the level of conservatism in reported earnings. The adjusted $\mathrm{R}^{2}$ of 14.84 is considerably higher than that observed for the regressions of Models (1) and (2), which indicates that Model (3) has more explanatory power.

Table 6 presents the results of the regression of Model (4) for all firm-year observations, rotation firm-year observations and no rotation firm-year observations. Although the variable $\beta_{3}$ is not significant for both the rotation and no rotation firm-years, it is much higher for the rotation firm-years. However, a z-test for the significance of the difference between coefficient $\beta_{3}$ of the rotation and no rotation firm-years indicated that the difference between the coefficients (1.1394) is not significant $(\mathrm{z}=1.52)$. This could largely be due to the higher standard error of coefficient $\beta_{3}(0.74)$ for the rotation firm-years compared to that of the no rotation firm-years (0.14).

Although, the lack of significance makes it impossible to accept Hypothesis 1 and conclude that there are higher levels of conservatism in reported earnings after rotation of the audit firm, the persistence of the observed effects is investigated.

\subsection{Earnings conservatism and audit firm tenure}

Following Johnson et al. (2002) the sample is partitioned into short, medium and long audit firm tenure firm-year observations, thus, at least 8 previous years of audit firm data was necessary. As a result, firm-year observations where the length of the tenure could not be accurately determined were deleted from the sample. This eventually resulted in a sample of 4,719 firm-year observations.

Since in the previous analysis the model of Ball and Shivakumar (2005) provided more significant results than that of Basu (1997), their method (Model (4)) was only used to test Hypothesis 2.

Table 7 presents descriptive statistics for the variables of Model (4), partitioned in the three audit firm tenure subsamples. Where the ACC variable seems to show a positive development as tenure lengthens, the CFO variable shows a negative development. Tests for significant differences between the three subsamples reveal that between the short and medium tenure subsamples and the medium and long tenure subsamples only the CFO variable differs significantly (respectively, $\mathrm{t}=2.53$ and $\mathrm{t}=2.40$ ).

There are far more firm-year observations in the long tenure subsample, compared to the short and medium tenure subsamples. Two reasons justify this distribution. First, short tenure spans a maximum of 3 years, and thus a maximum of 3 firm-years per auditor-client relationship could be included, where medium tenure spans a maximum of 5 firm-years and long tenure spans, theoretically, an indefinite number of firm-years that could be included in the sample. Second, according to the GAO (2003) report, the average audit firm tenure for Fortune 1000 public companies is 22 years, which indicates that more firm-year observations of long tenure is not unusual.

Table 8 presents the results of the regression for the three tenure subsamples. A positive and significant coefficient $\beta_{3}$ is found for the short tenure subsample compared to a positive, but insignificant coefficient $\beta_{3}$ for the medium tenure subsample and a negative and significant coefficient $\beta_{3}$ for the long tenure subsample. 
Significance tests for the differences between coefficients $\beta_{3}$ for the three subsamples indicate a significant difference between the short and long tenure $(\mathrm{z}=4.02)$ and the medium and long tenure $(\mathrm{z}=2.04)$ subsamples.

The results indicate a negative association between the length of the audit firm tenure and the level of conservatism in reported earnings. Although this association cannot be exactly determined for medium tenure because coefficient $\beta_{3}$ lacks significance for that subsample, the significant difference between the short and long tenure subsamples provides evidence in favour of Hypothesis 2.

The results are not consistent with the findings of Jenkins and Velury (2008), who found that earnings conservatism increases between short and medium tenure, and not completely consistent with those of Hamilton et al. (2005), who documented continued conservatism in earnings after the initial years of the auditor-client relationship. This continuation does not emerge from the results presented in Table 8, since they suggest a progressive decline in earnings conservatism as audit firm tenure lengthens. But, since coefficient $\beta_{3}$ is highly insignificant for the medium tenure sample, the exact progress is uncertain. A continuation of the level of conservatism in earnings between short and medium tenure is therefore not inconceivable. The results further contradict the evidence of Myers et al. (2003) that earnings quality increases with auditor tenure. Finally, the results confirm the perceptions of shareholders that longer auditor tenure adversely affects earnings quality, as documented by Dao et al. (2008).

\subsection{Additional analysis}

Additional tests, as outlined by prior research, were applied to provide more depth into the analysis and guarantee the robustness of the results.

\subsubsection{Big N vs. non-Big $\mathrm{N}$ audit firms}

Evidence exists that earnings of firms audited by Big $\mathrm{N}$ audit firms have superior quality compared to firms audited by non-Big N audit firms (e.g. Krishnan, 2003). Further, Hamilton et al. (2005) found that audit partner rotation is only associated with an increase in earnings conservatism for Big Five audit clients. Basu et al. (2000) argued that, because of a greater exposure to legal liability, Big Eight audit firms have incentives to determine earnings more conservatively than non-Big Eight audit firms do. Further, Francis and Krishnan (1999) found that Big Six audit firms report more conservative than non-Big Six audit firms. It can thus be expected that any association between audit firm rotation and earnings conservatism is stronger for Big $\mathrm{N}$ clients than for non-Big $\mathrm{N}$ clients.

To investigate this, Model (3) is replicated with a Big N $(n=11,185)$ and a non-Big N $(n=458)$ subsample. The results presented in Table 9 show a significantly positive association between audit firm rotation and the level of conservatism in earnings of Big $\mathrm{N}$ clients, as measured by coefficient $\beta_{7}$. This is consistent with Big $\mathrm{N}$ clients having higher earnings quality as indicated by prior research. Audit firm rotation does not seem to have an effect on the level of earnings conservatism for non-Big $\mathrm{N}$ clients, since $\beta_{7}$ is negative and highly insignificant for the non-Big N sample. Based on the results in Table 9 it can be concluded that the effect of audit firm rotation on the level of conservatism in reported earnings only exists for clients of Big $\mathrm{N}$ audit firms. This is an indication that if audit firm rotation would be mandated, it should not be unilaterally applied to clients of both Big N and non-Big $\mathrm{N}$ audit firms, because its effects seem to differ significantly. However, conclusions have to be drawn with caution, since the difference in the number of firm-year observations in the subsamples is very large.

To test whether the inclusion of the non-Big $\mathrm{N}$ client firm-year observations in the sample have affected the results presented earlier, all regressions of the initial analysis were redone using only the Big $\mathrm{N}$ sample. The results did not indicate any significant differences with the results presented earlier.

\subsubsection{Changes in the accounting and auditing environment}

With regard to regulation and litigation, significant changes took place in the accounting environment during 2001-2003. For instance, as an answer to the accounting scandals, SOX required rotation of audit partners after 5 years. Our study does not focus on audit firm rotation in a mandatory environment, since such an environment does not exists. It rather investigates the effects of audit firm rotation in general. However, since mandatory rotation of audit partners became effective during the sample period, not partitioning the sample could have caused a bias in the results.

Jenkins and Velury (2008) stated that mandatory auditor rotation could have an adverse effect on conservatism in reported earnings, since their results indicated lower levels of conservatism for short auditor tenure. However, the results presented earlier do not correspond with that statement. Rather, since audit firm rotation seems to be accompanied with more conservative reporting, and Hamilton et al. (2005) found an increase in conservative reporting after audit partner rotation, it would be expected that higher levels of conservatism are more likely in the last part of the sample period, where partner rotation was a mandatory requirement. Whether this would be particularly due to mandatory auditor rotation could be questioned. Prior research has documented several factors that have influenced conservatism in earnings. For example, Gassen and Sellhorn (2006) found that financial reporting under IFRS is more conservative than German GAAP. Further, Lobo and Zhou (2006) found that conservatism in reported earnings has generally increased after the issue of SOX. This would be consistent 
with Basu (1997), who argued that accounting conservatism in the U.S. has increased due to new accounting standards.

In order to investigate the influence of new regulations in the accounting and auditing environment on the association between earnings conservatism and audit firm rotation, the initial analysis using Model (3) is repeated with a time partitioned sample. These samples consist of firm-year observations for, respectively, the periods 1981-2000, 2001-2003 and 2004-2006. The results of the regressions are shown in Table 10.

The results show an increasing coefficient $\beta_{3}$ over the entire sample period, indicating that conservatism has increased. A z-test indicated that the coefficient $\beta_{3}$ only differs significantly between the 1981-2000 and the 2004-2006 subsamples $(z=-2.35)$. The results confirm the evidence that conservatism in earnings has increased after SOX (Lobo and Zhou, 2006) and over time (Basu, 1997), (Note 12), but they seem to be inconsistent with the statement by Jenkins and Velury (2008) that mandatory auditor rotation has an adverse effect on the reporting of conservative earnings. However, the results show a progressive decline for coefficient $\beta_{7}$, which indicates that the association between audit firm rotation and earnings conservatism has weakened over time. Coefficient $\beta_{7}$ differs significantly between the 1981-2000 and the 2001-2003 subsamples $(z=2.37)$, the 2001-2003 and the 2004-2006 subsamples $(\mathrm{z}=2.98)$ and, consequently, between the 1981-2000 and the 2004-2006 subsamples $(\mathrm{z}=$ 4.89). It thus appears that, towards the end of the sample period, audit firm rotation has not been a particular factor causing earnings conservatism (Note 13). The investigation of this observation, however, does not lie in the scope of this study and is something future research should examine. Rather, of interest for our work is that the results presented in Table 10 provide evidence that the effects of audit firm rotation do not seem to be consistent over the entire sample period. Any favourable effects of audit firm rotation on the quality of earnings do not seem to exist in the later part of the sample period.

\section{Discussion-Conclusions}

This study has failed to provide sufficient significant evidence in favour of the hypothesis that audit firm rotation is accompanied by an increase in the level of conservatism in reported earnings. However, this should not be considered as evidence that conservatism in earnings does not increase after audit firm rotation, since the signs and values of the coefficients indicate that such an association exists.

Our work showed that levels of conservatism in reported earnings are higher for short audit firm tenure than they are for long audit firm tenure. This is inconsistent with prior research (e.g. Johnson et al., 2002; Myers et al., 2003), and it may be due to the different proxies on earnings quality used. The findings in our study do not undermine the results of prior research, but they indicate that when drafting regulations, standard setters should not limit their focus on research that examines only associations between auditor rotation and one specific proxy for earnings quality.

Several insights from prior research might have influenced our results and could provide explanations for their insignificance regarding Hypothesis 1. A first issue is that the type of audit opinion issued is not taken into consideration in the analysis employed in this work. Chow and Rice (1982) have documented a positive association between the receipt of a qualified opinion in the year prior to an auditor switch and the client's propensity to switch auditor. Receiving a qualified opinion might be due to instances of overly aggressive reporting which could blur the association investigated here. On the other hand, one could question whether the type of opinion issued by the previous audit firm, affects the level of conservatism demanded by the new audit firm.

This study contributes to the existing literature in that our results suggest that mandating audit firm rotation might have a positive effect on the asymmetric timeliness of loss recognition (i.e. conservatism). Another contribution is that we examine contradicting evidence resulted from prior research. Further, it contributes by indicating that regulation with regard to audit firm rotation should not be unilaterally applied to Big $\mathrm{N}$ and non-Big $\mathrm{N}$ audit firms.

\section{Study Limitations and Recommendations}

Although our research provides some evidence in favour of mandatory audit firm rotation, one has to take a critical view of our findings due to several limitations. First, our study was not conducted during a period in which audit firm rotation was mandatory. According to Dopuch et al. (2001) it is difficult to obtain evidence regarding the effects of proposed regulation before it is implemented. Our results might thus not exactly fit a mandatory audit firm rotation environment, since clients and auditors might then face different incentives (Jenkins and Velury, 2008; Chi et al., 2009). Second, different factors could have affected the rotation of an audit firm, such as the type of audit opinion (Chow and Rice, 1982), reporting disputes, and management changes (Schwartz and Menon, 1985). These factors could have had an influence on the reported numbers used for the analysis here.

Following the results of our work, several issues could be investigated for future research. The effect of the type of audit opinion issued on the association between earnings quality and auditor rotation should be investigated. Further, as a more practical issue for accountants and auditors, future research could examine in which specific accounts an increase in conservatism is observed after audit firm rotation and what the underlying factors of 
these increases are. Next, it could be investigated to what extent institutional factors affect the assessments of possible consequences of mandatory auditor rotation. It seems that this has not been researched so far. Ball et al. (2000) have documented a variation in the level of conservatism across different countries. They found that earnings in common-law countries were significantly more conservative than code-law countries, which is entirely due to quicker incorporation of losses. Thus, conducting this same analysis to code-law countries would provide the necessary evidence to generalise the findings of our research.

Finally, in our study we have argued that conservatism is an important attribute of earnings quality. There is no evidence, however, on what the importance of conservatism relative to other attributes is. Whether our results can be used in the debate around mandatory auditor rotation depends on the weight one assigns to conservatism as an attribute of earnings quality. One has to keep in mind that all implications our results might carry are based on the condition that the level of conservatism in reported earnings is a good measure for the quality of those earnings. Conservatism is only one aspect of financial reporting. Therefore, decisions regarding regulation should also rely on research examining the effects of audit firm rotation on other measures of earnings quality.

\section{References}

Amir, E., Guan, Y., \& Livne, G. (2009). The association between auditor independence and conservatism. Working paper, City University of London, The University of Hong Kong and London Business School.

Antle, R., \& Nalebuff, B. (1991). Conservatism and auditor-client negotiations. Journal of Accounting Research, 29 (Supplement), 31-54.

Ball, R., Kothari, S.P., \& Robin, A. (2000). The effect of international institutional factors on properties of accounting earnings. Journal of Accounting and Economics, 29, (1), 1-51.

Ball, R., \& Shivakumar, L. (2005). Earnings quality in UK private firms: comparative loss recognition timeliness. Journal of Accounting and Economics, 39, 83-128.

Basu, S. (1997). The conservatism principle and the asymmetric timeliness of earnings. Journal of Accounting and Economics, 24, 3-37.

Basu, S., Hwang, L., \& Jan, C. (2000). Differences in conservatism between Big Eight and non-Big Eight auditors. Working paper, City University of New York and California State University.

Basu, S., Hwang, L., \& Jan, C. (2001). Auditor conservatism and quarterly earnings. Working paper, City University of New York and California State University.

Beaver, W., Lambert, R., \& Morse, D. (1980). The information content of security prices. Journal of Accounting and Economics, 2, (1), 3-28.

Brame, R., Paternoster, R., Mazerolle, P., \& Piquero, A. (1998). Testing for the equality of maximum-likelihood regression coefficients between two independent equations. Journal of Quantitative Criminology, 14, (3), 245-261.

Cameran, M., Di Vincenzo, D., \& Merlotti, E. (2005). The audit firm rotation rule: A review of the literature. Working paper, Bocconi University, Milan, Italy. [Online] Available: http://ssrn.com/abstract=825404.

Carcello, J., \& Nagy, A. (2004). Audit firm tenure and fraudulent financial reporting. Auditing: A Journal of Practice and Theory, 23, (2), 55-69.

Chen, C., Lin, C., \& Lin, Y. (2008). Audit partner tenure, audit firm tenure, and discretionary accruals: Does long auditor tenure impair earnings quality? Contemporary Accounting Research, 25, (2), 415-445.

Chi, W., Huang, H., Liao, Y., \& Xie, H. (2009). Mandatory audit partner rotation, audit quality, and market perception: Evidence from Taiwan. Contemporary Accounting Research, 26, (2), 359-391.

Choi, S., \& Jeter, D. (1992). The effects of qualified audit opinions on earnings response coefficients. Journal of Accounting and Economics, 15, (2), 229-247.

Chow, C.W., \& Rice, S.J. (1982). Qualified audit opinions and auditor switching. The Accounting Review, 57, 326-335.

Christie, A.A. (1987). On cross-sectional analysis in accounting research. Journal of Accounting and Economics, 9, 231-258.

Dao, M., Mishra, S., \& Raghunandan, K. (2008). Auditor tenure and shareholder ratification of the auditor. Accounting Horizons, 22, (3), 297-314.

Davis, L.R., Soo, B., \& Trompeter, G. (2000). Auditor tenure, auditor independence and earnings management. Working paper, Michigan Tech University and Boston College.

Dopuch, N., King, R., \& Schwartz, R. (2001). An Experimental Investigation of Retention and Rotation Requirements. Journal of Accounting Research, 39, (1), 93-117.

Financial Accounting Standards Board (FASB). (1980). Statement of Financial Accounting Concept No. 2: Qualitative Characteristics of Accounting Information. Stamford, CN: FASB. 
Francis, J.R., \& Krishnan, J. (1999). Accounting accruals and auditor reporting conservatism. Contemporary Accounting Research, 16, (1), 135-165.

Francis, J., LaFond, R., Olssen, P., \& Schipper, K. (2005). The market pricing of accruals quality. Journal of Accounting and Economics, 39, (2), 295-327.

Gassen, J., \& Sellhorn, T. (2006). Applying IFRS in Germany - Determinants and consequences. Betriebswirtschaftliche Forschung und Praxis, 58, (4), 365-386.

Geiger, M., \& Raghunandan, K. (2002). Auditor tenure and audit reporting failures. Auditing: A Journal of Practice and Theory, 21, (1), 67-78.

Ghosh, A., \& Moon, D. (2004). Auditor tenure and perceptions of audit quality. The Accounting Review, 80, (2), 585-612.

Givoly, D., \& Hayn, C. (2000). The changing time-series properties of earnings, cash flows and accruals: Has financial reporting become more conservative? Journal of Accounting and Economics, 29, (3), 287-320.

Givoly, D., Hayn, C., \& Natarajan, A. (2007). Measuring reporting conservatism. The Accounting Review, 82, (1), 65-106.

Hackenbrack, K., \& Nelson, M.W. (1996). Auditors' incentives and their application of financial accounting standards. The Accounting Review, 71, (1), 43-59.

Hamilton, J., Ruddock, C., Stokes, D., \& Taylor, S. (2005). Audit partner rotation, earnings quality and earnings conservatism. Working paper, University of Technology, Sydney and University of New South Wales. [Online] Available: http://ssrn.com/abstract $=740846$.

Hatfield, R.C., Jackson, S.B., \& Vandervelde, S.D. (2007). The effects of auditor rotation and client pressure on proposed audit adjustments. Working paper, University of Alabama.

Imhoff, E.A. (2003). Accounting quality, auditing, and corporate governance. Accounting Horizons, Supplement 2003, 117-128.

Jackson, A.B., Moldrich, M., \& Roebuck, P. (2008). Mandatory audit firm rotation and audit quality. Managerial Auditing Journal, 23, (5), 420-437.

Jenkins, D., \& Velury, U. (2008). Does auditor tenure influence the reporting of conservative earnings? Journal of Accounting and Public Policy, 27, 115-132.

Johnson, V., Khurana, I., \& Reynolds, J. (2002). Audit-firm tenure and the quality of financial reports. Contemporary Accounting Research, 19, (4), 637-660.

Kaplan, S., \& Mauldin, E. (2008). Auditor rotation and the appearance of independence: Evidence from non-professional investors. Journal of Accounting and Public Policy, 27, 177-192.

Krishnan, G. (2003). Audit quality and the pricing of discretionary accruals. Auditing: A Journal of Practice and Theory, 22, (March), 109-126.

Lobo, G.J., \& Zhou, J. (2006). Did conservatism in financial reporting increase after the Sarbanes-Oxley Act? Initial evidence. Accounting Horizons, 20, (1), 57-73.

Myers, J., Myers, L., \& Omer, T. (2003). Exploring the term of the auditor-client relationship and the quality of earnings: A case for mandatory auditor rotation? The Accounting Review, 78, (3), 779-799.

Ryan, S.G. (2006). Identifying conditional conservatism. European Accounting Review, 15, (4), 511-525.

Sarbanes-Oxley Act (SOX). (2002). Public Law No. 107-204. Washington, DC: Government Printing Office.

Stice, J. (1991). Using financial and market information to identify pre-engagement factors associated with lawsuits against auditors. The Accounting Review, 66, (3), 516-533.

Schwartz, K.B., Menon, K. (1985). Auditor switches by failing firms. The Accounting Review, 60, (2), 248-261.

U.S. General Accounting Office (GAO). (2003). Public Accounting Firms: Required Study on the Potential Effects of Mandatory Audit Firm Rotation. Washington DC: Government Printing Office.

Wang, K.J., \& Tuttle, B.M. (2009). The impact of auditor rotation on auditor-client negotiation. Accounting, Organizations and Society, 34, 222-243.

Watts, R. (2003a). Conservatism in accounting part I: Explanations and implications. Accounting Horizons, 17, (3), 207-221.

Watts, R. (2003b). Conservatism in accounting part II: Evidence and research opportunities. Accounting Horizons, 17, (4), 287-301.

\section{Notes}

Note 1. For a broad overview of research on auditor rotation see Cameran et al. (2005).

Note 2. Only in Taiwan and Australia are audit partner names publicly available (Hamilton et al., 2005; Chi et al., 2009). 
Note 3. The lead audit partner is the partner having primary responsibility for the audit.

Note 4. See Watts (2003a, 2003b) for an extensive analysis of literature regarding conservatism and its role in accounting.

Note 5. Critics regarding Basu's (1997) measure can, inter alia, be found in Ball and Shivakumar (2005) and Givoly et al. (2007).

Note 6. Basu (1997) used the following model: $X_{i t} / P_{i t-1}=\alpha_{0}+\alpha_{1} D R_{i t}+\beta_{0} R_{i t}+\beta_{1} R_{i t} * D R_{i t}$.

Note 7. Let $\mathrm{P}_{\mathrm{it}}$ denote the stock price of firm $i$ at the end of fiscal-year t, then $\mathrm{RET}_{\mathrm{it}}$ can be calculated as $\left(\mathrm{P}_{\mathrm{it}}-\mathrm{P}_{\mathrm{it}-1}\right)$ $/ \mathrm{P}_{\text {it-1. }}$.

Note 8. No specific reasoning underlies the choice of the beginning and the ending years of the sample period.

Note 9. This follows prior research by, inter alia, Hamilton et al. (2005), Givoly et al. (2007) and Jenkins and Velury (2008).

Note 10. Coopers \& Lybrand merged with Pricewaterhouse in 1998 to form PricewaterhouseCoopers, Touche Ross merged with Deloite, Haskins and Sells in 1989 to form Deloitte \& Touche, Arthur Young merged with Ernst \& Whinney in 1989 to form Ernst \& Young, Peat Marwick merged with Klynveld Main Goerdeler in 1987 to form KPMG.

Note 11. The z-test employed in this paper, testing for the differences between regression coefficients is taken from Brame et al. (1998).

Note 12. When Model (4) is applied to test for conservatism in the three subsamples, similar values are obtained for coefficient $\beta_{3}$ which do not significantly differ from the values presented in Table10.

Note 13. When the Basu (1997) method is used to repeat the analysis, similar results are obtained.

Table 1. Descriptive statistics for the sample variables

\begin{tabular}{|c|c|c|c|c|c|c|c|}
\hline \multicolumn{8}{|c|}{ Panel A: entire sample $(n=11,643)$} \\
\hline \multicolumn{2}{|c|}{\begin{tabular}{l|l} 
Variable & \\
\end{tabular}} & Mean & Median & \multicolumn{2}{|c|}{ Std. dev. } & Minimum & Maximum \\
\hline \multicolumn{2}{|l|}{$E A R N$} & 0.0016 & 0.0006 & \multicolumn{2}{|c|}{0.0093} & -0.0839 & 0.0519 \\
\hline$R E T$ & \multicolumn{2}{|c|}{-0.0527} & -0.0414 & \multicolumn{2}{|l|}{0.3692} & -1.3333 & 0.9596 \\
\hline DRET & \multicolumn{2}{|c|}{0.5446} & 1.000 & \multicolumn{2}{|l|}{0.4980} & 0.000 & 1.000 \\
\hline \begin{tabular}{l|l}
$R O T A T$ & \\
\end{tabular} & \multicolumn{2}{|c|}{0.0395} & 0.000 & \multicolumn{2}{|c|}{0.1948} & 0.000 & 1.000 \\
\hline \multicolumn{8}{|c|}{ Panel B: partitioned by audit firm rotation } \\
\hline & \multicolumn{3}{|c|}{$\begin{array}{c}\text { Audit firm rotation } \\
(\mathrm{n}=460)\end{array}$} & \multicolumn{3}{|c|}{$\begin{array}{c}\text { No audit firm rotation } \\
(\mathrm{n}=11,183)\end{array}$} & $\begin{array}{c}\text { Significance } \\
\text { test }\end{array}$ \\
\hline Variable & Mean & Median & \begin{tabular}{l|l} 
Std. dev. \\
\end{tabular} & Mean & Median & Std. dev. & T-test \\
\hline$E A R N$ & 0.0005 & 0.0006 & 0.0122 & 0.0017 & 0.0006 & 0.0091 & $-1.99 *$ \\
\hline$R E T$ & -0.0126 & 0.0041 & 0.3928 & -0.0544 & -0.0431 & 0.3681 & $2.24 *$ \\
\hline DRET & 0.4913 & 0.0000 & 0.5005 & 0.5468 & 1.0000 & 0.4978 & $-2.33 *$ \\
\hline
\end{tabular}

Table 2. Coefficients and adjusted $\mathrm{R}^{2} \mathrm{~s}(\%)$ from pooled cross-sectional regressions of Model (1)

\begin{tabular}{|l|c|c|c|c|c|c|}
\hline & $\mathbf{n}$ & $\boldsymbol{\beta}_{\mathbf{0}}$ & $\boldsymbol{\beta}_{\mathbf{1}}$ & $\boldsymbol{\beta}_{\mathbf{2}}$ & $\boldsymbol{\beta}_{\mathbf{3}}$ & $\mathbf{A d j}_{\mathbf{2}} \mathbf{R}^{\mathbf{2}}$ \\
\hline \multirow{2}{*}{ All firm-years } & \multirow{2}{*}{11,643} & $0.0017^{* *}$ & $-0.0038^{* *}$ & -0.0000 & $0.0231^{* *}$ & \multirow{2}{*}{5.80} \\
\cline { 3 - 6 } & & $(0.00)$ & $(0.00)$ & $(0.96)$ & $(0.00)$ & \\
\hline \multirow{2}{*}{ Rotation firm-years } & \multirow{2}{*}{460} & 0.0011 & $-0.0071^{* *}$ & -0.0005 & $0.0288^{* *}$ & \multirow{2}{*}{9.26} \\
\cline { 3 - 6 } & & $(0.25)$ & $(0.00)$ & $(0.77)$ & $(0.00)$ & \\
\hline \multirow{2}{*}{ No rotation firm-years } & \multirow{2}{*}{11,183} & $0.0017^{* *}$ & $-0.0036^{* *}$ & 0.0000 & $0.0226^{* *}$ & \multirow{2}{*}{5.57} \\
\cline { 3 - 6 } & & $(0.00)$ & $(0.00)$ & $(0.95)$ & $(0.00)$ & \\
\hline
\end{tabular}

* significant at the two-tailed $5 \%$ confidence level

$* *$ significant at the two-tailed $1 \%$ confidence level

p-values between brackets 
Table 3. Coefficients and adjusted $\mathrm{R}^{2}(\%)$ from pooled cross-sectional regressions of Model (2)

\begin{tabular}{|c|c|c|c|c|c|c|c|c|}
\hline $\boldsymbol{\beta}_{\mathbf{0}}$ & $\boldsymbol{\beta}_{\mathbf{1}}$ & $\boldsymbol{\beta}_{\mathbf{2}}$ & $\boldsymbol{\beta}_{\mathbf{3}}$ & $\boldsymbol{\beta}_{\mathbf{4}}$ & $\boldsymbol{\beta}_{\mathbf{5}}$ & $\boldsymbol{\beta}_{\mathbf{6}}$ & $\boldsymbol{\beta}_{\mathbf{7}}$ & Adj. $\mathbf{R}^{\mathbf{2}}$ \\
\hline $0.0017^{* *}$ & $-0.0036^{* *}$ & 0.0000 & $0.0229^{* *}$ & 0.0004 & $-0.0073^{* *}$ & -0.0010 & 0.0056 & \multirow{2}{*}{5.90} \\
\hline$(0.00)$ & $(0.00)$ & $(0.95)$ & $(0.00)$ & $(0.69)$ & $(0.01)$ & $(0.48)$ & $(0.11)$ & \\
\hline
\end{tabular}

* significant at the two-tailed $5 \%$ confidence level

** significant at the two-tailed $1 \%$ confidence level

p-values between brackets

Table 4. Descriptive statistics for Model (3)

\begin{tabular}{|c|c|c|c|c|c|c|c|c|}
\hline \multicolumn{9}{|c|}{ Panel A: entire sample $(n=11,643)$} \\
\hline Variable & \multicolumn{2}{|c|}{\begin{tabular}{l|l|} 
& Mean
\end{tabular}} & Median & \multicolumn{2}{|c|}{ Std. dev. } & & inimum & Maximum \\
\hline$A C C$ & \multicolumn{2}{|c|}{0.0009} & 0.0005 & \multicolumn{2}{|c|}{0.0093} & & -0.0839 & 0.0519 \\
\hline CFO & \multicolumn{2}{|c|}{0.0008} & 0.0001 & \multicolumn{2}{|c|}{0.0026} & & -0.0080 & 0.0198 \\
\hline$D C F O$ & \multicolumn{2}{|c|}{0.2735} & 0.0000 & \multicolumn{2}{|c|}{0.4458} & & 0.0000 & 1.0000 \\
\hline ROTAT & \multicolumn{2}{|c|}{0.0395} & 0.0000 & \multicolumn{2}{|c|}{0.1948} & & 0.0000 & 1.0000 \\
\hline \multicolumn{9}{|c|}{ Panel B: partitioned by audit firm rotation } \\
\hline & \multicolumn{3}{|c|}{$\begin{array}{c}\text { Audit firm rotation } \\
(\mathrm{n}=460)\end{array}$} & \multicolumn{4}{|c|}{$\begin{array}{c}\text { No audit firm rotation } \\
(\mathrm{n}=11,183)\end{array}$} & $\begin{array}{c}\text { Significance } \\
\text { test }\end{array}$ \\
\hline Variable & Mean & Median & Std. dev. & Mean & & & Std. dev. & T-test \\
\hline$A C C$ & -0.0005 & 0.0004 & 0.0132 & 0.0009 & & & 0.0098 & $-2.27 *$ \\
\hline CFO & 0.0010 & 0.0002 & 0.0032 & 0.0008 & & & 0.0025 & 1.78 \\
\hline$D C F O$ & 0.2848 & 0.0000 & 0.4518 & 0.2730 & & & 0.4455 & 0.55 \\
\hline
\end{tabular}

* significant at the two-tailed $5 \%$ confidence level

Table 5. Coefficients and adjusted $\mathrm{R}^{2}(\%)$ from pooled cross-sectional regressions for Model (3)

\begin{tabular}{|c|c|c|c|c|c|c|c|c|}
\hline $\boldsymbol{\beta}_{\mathbf{0}}$ & $\boldsymbol{\beta}_{\mathbf{1}}$ & $\boldsymbol{\beta}_{\mathbf{2}}$ & $\boldsymbol{\beta}_{\mathbf{3}}$ & $\boldsymbol{\beta}_{\mathbf{4}}$ & $\boldsymbol{\beta}_{\mathbf{5}}$ & $\boldsymbol{\beta}_{\mathbf{6}}$ & $\boldsymbol{\beta}_{\mathbf{7}}$ & \multirow{2}{*}{ Adj. $\mathbf{R}^{\mathbf{2}}$} \\
\hline $0.0021^{* *}$ & $-1.4904^{* *}$ & 0.0001 & 0.2564 & 0.0000 & $-0.4374 * *$ & -0.0009 & $1.1393^{*}$ & \multirow{2}{*}{14.84} \\
\hline$(0.00)$ & $(0.00)$ & $(0.73)$ & $(0.08)$ & $(0.95)$ & $(0.01)$ & $(0.41)$ & $(0.05)$ & \\
\hline
\end{tabular}

* significant at the two-tailed $5 \%$ confidence level

** significant at the two-tailed $1 \%$ confidence level

p-values between brackets

Table 6. Coefficients and adjusted $\mathrm{R}^{2} \mathrm{~s}(\%)$ from pooled cross-sectional regressions of Model (4)

\begin{tabular}{|l|c|c|c|c|c|c|}
\hline & $\mathbf{n}$ & $\boldsymbol{\beta}_{\mathbf{0}}$ & $\boldsymbol{\beta}_{\mathbf{1}}$ & $\boldsymbol{\beta}_{\mathbf{2}}$ & $\boldsymbol{\beta}_{\mathbf{3}}$ & Adj. $\mathbf{R}^{\mathbf{2}}$ \\
\hline \multirow{2}{*}{ All firm-years } & \multirow{2}{*}{11,643} & $0.0021^{* *}$ & $1.5171^{* *}$ & 0.0000 & $0.3423^{* *}$ & \multirow{2}{*}{14.76} \\
\cline { 3 - 6 } & & $(0.00)$ & $(0.00)$ & $(0.84)$ & $(0.01)$ & \\
\hline \multirow{2}{*}{ Rotation firm-years } & \multirow{2}{*}{460} & $0.0021^{* *}$ & $1.9278^{* *}$ & 0.0009 & 1.3958 & \multirow{2}{*}{17.49} \\
\cline { 3 - 6 } & & $(0.01)$ & $(0.00)$ & $(0.55)$ & $(0.06)$ & \\
\hline \multirow{2}{*}{ No rotation firm-years } & \multirow{2}{*}{11,183} & $0.0021^{* *}$ & $1.4904^{* *}$ & 0.0001 & 0.2564 & \multirow{2}{*}{14.58} \\
\cline { 3 - 6 } & & $(0.00)$ & $(0.00)$ & $(0.72)$ & $(0.07)$ & \\
\hline
\end{tabular}

* significant at the two-tailed $5 \%$ confidence level

** significant at the two-tailed $1 \%$ confidence level

p-values between brackets

Table 7. Descriptive statistics partitioned by audit firm tenure $(n=4,719)$

\begin{tabular}{|l|c|c|c|c|c|c|}
\hline & \multicolumn{2}{|c|}{ Short tenure* $(\mathrm{n}=1,074)$} & \multicolumn{2}{c|}{ Medium tenure $\dagger(\mathrm{n}=672)$} & \multicolumn{2}{c|}{ Long tenure $\ddagger(\mathrm{n}=2,973)$} \\
\hline Variable & Mean & Median & Mean & Median & Mean & Median \\
\hline$A C C$ & -0.0005 & 0.0004 & 0.0002 & 0.0004 & 0.0009 & 0.0003 \\
\hline$C F O$ & 0.0010 & 0.0002 & 0.0007 & 0.0001 & 0.0005 & 0.0001 \\
\hline$D C F O$ & 0.2663 & 0.000 & 0.2946 & 0.000 & 0.2661 & 0.000 \\
\hline
\end{tabular}

* Auditor-client relationship of two to three years

$\dagger$ Auditor-client relationship of four to eight years

$\$$ Auditor-client relationship of nine or more years 
Table 8. Coefficients and adjusted $\mathrm{R}^{2} \mathrm{~s}(\%)$ from pooled cross-sectional regressions of Model (4)

\begin{tabular}{|l|l|l|l|l|l|l|}
\hline & $\mathbf{n}$ & $\boldsymbol{\beta}_{\mathbf{0}}$ & $\boldsymbol{\beta}_{\mathbf{1}}$ & $\boldsymbol{\beta}_{\mathbf{2}}$ & $\boldsymbol{\beta}_{\mathbf{3}}$ & \multirow{2}{*}{ Adj. $\mathbf{R}^{\mathbf{2}}$} \\
\hline \multirow{2}{*}{ Short tenure } & \multirow{2}{*}{1,074} & $0.0022^{* *}$ & $-2.0631^{* *}$ & -0.0011 & $1.1540^{*}$ & \multirow{2}{*}{26.08} \\
\cline { 3 - 6 } & & $(0.00)$ & $(0.00)$ & $(0.18)$ & $(0.01)$ & \\
\hline \multirow{2}{*}{ Medium tenure } & \multirow{2}{*}{672} & $0.0016^{* *}$ & $-2.0301^{* *}$ & 0.0002 & 0.3671 & \multirow{2}{*}{34.09} \\
\cline { 3 - 7 } & & $(0.00)$ & $(0.00)$ & $(0.73)$ & $(0.52)$ & \\
\hline \multirow{2}{*}{ Long tenure } & \multirow{2}{*}{2,973} & $0.0015^{* *}$ & $-1.2763^{* *}$ & -0.0003 & $-0.8826^{* *}$ & \multirow{2}{*}{14.58} \\
\cline { 3 - 6 } & & $(0.00)$ & $(0.00)$ & $(0.3366)$ & $(0.00)$ & \\
\hline
\end{tabular}

* significant at the two-tailed $5 \%$ confidence level

** significant at the two-tailed $1 \%$ confidence level

p-values between brackets

Table 9. Coefficients and adjusted $\mathrm{R}^{2} \mathrm{~S}(\%)$ from pooled cross-sectional regressions of Model (3)

\begin{tabular}{|c|c|c|c|c|c|c|c|c|}
\hline $\boldsymbol{\beta}_{0}$ & $\beta_{1}$ & $\boldsymbol{\beta}_{2}$ & $\boldsymbol{\beta}_{3}$ & $\boldsymbol{\beta}_{4}$ & $\beta_{5}$ & $\beta_{6}$ & $\boldsymbol{\beta}_{7}$ & Adj. $R^{2}$ \\
\hline \multicolumn{9}{|c|}{ Panel A: Big N sample $(n=11,185)$} \\
\hline $0.0020 * *$ & $1.4324 * *$ & 0.0001 & 0.0474 & 0.0003 & $0.6255^{* *}$ & 0.0008 & $1.2475^{*}$ & \multirow{2}{*}{15.03} \\
\hline$(0.00)$ & $(0.00)$ & $(0.78)$ & $(0.74)$ & $(0.60)$ & $(0.00)$ & $(0.48)$ & $(0.03)$ & \\
\hline \multicolumn{9}{|c|}{ Panel B: non-Big N sample $(n=458)$} \\
\hline $0.0039 * *$ & $-2.4307 * *$ & 0.0043 & 6.6092 & 0.0010 & 0.8414 & -0.0049 & -2.8646 & \multirow{2}{*}{17.47} \\
\hline$(0.00)$ & $(0.00)$ & $(0.13)$ & $(0.00)$ & $(0.74)$ & $(0.24)$ & $(0.43)$ & $(0.43)$ & \\
\hline
\end{tabular}

$*$ significant at the two-tailed $5 \%$ confidence level

$* *$ significant at the two-tailed $1 \%$ confidence level

p-values between brackets

Table 10. Coefficients and adjusted $\mathrm{R}^{2} \mathrm{~s}(\%)$ from pooled cross-sectional regressions of Model (3)

\begin{tabular}{|c|c|c|c|c|c|c|c|c|}
\hline $\boldsymbol{\beta}_{0}$ & $\beta_{1}$ & $\boldsymbol{\beta}_{2}$ & $\beta_{3}$ & $\beta_{4}$ & $\beta_{5}$ & $\beta_{6}$ & $\boldsymbol{\beta}_{7}$ & Adj. $R^{2}$ \\
\hline \multicolumn{9}{|c|}{ Panel A: $1981-2000(n=8,087)$} \\
\hline $0.0025 * *$ & $1.4549 * *$ & 0.0001 & 0.1893 & 0.0004 & 1.0869 & 0.0004 & $2.5842 * *$ & \multirow{2}{*}{14.11} \\
\hline$(0.00)$ & $(0.00)$ & $(0.73)$ & $(0.27)$ & $(0.72)$ & $(0.00)$ & $(0.85)$ & $(0.00)$ & \\
\hline \multicolumn{9}{|c|}{ Panel B: 2001-2003 $(n=1,815)$} \\
\hline $0.0011 * *$ & $1.7823 * *$ & 0.0001 & $0.8843^{*}$ & 0.0014 & 0.0727 & $0.0029 *$ & -0.4410 & \multirow{2}{*}{23.82} \\
\hline$(0.00)$ & $(0.00)$ & $(0.80)$ & $(0.03)$ & $(0.07)$ & $(0.72)$ & $(0.05)$ & $(0.65)$ & \\
\hline \multicolumn{9}{|c|}{ Panel C: 2004-2006 $(n=1,741)$} \\
\hline $0.0015^{* *}$ & $-1.5898 * *$ & -0.0003 & $1.1261 * *$ & -0.0010 & $2.3921 * *$ & 0.0019 & $-5.8402 * *$ & \multirow{2}{*}{17.06} \\
\hline$(0.00)$ & $(0.00)$ & $(0.49)$ & $(0.00)$ & $(0.30)$ & $(0.00)$ & $(0.32)$ & $(0.00)$ & \\
\hline
\end{tabular}

* significant at the two-tailed $5 \%$ confidence level

** significant at the two-tailed $1 \%$ confidence level

p-values between brackets 